\title{
Optimization Design on Slab Chamfered-Mold Taper by Using FEM
}

\author{
Liu Yang Wang Wei-hua Ma Chang-wen \\ ShouGang Research Institute of Technology, Beijing 100043, China
}

\begin{abstract}
In order to solve the gap appears frequently on chamfer slab in the chamfered position and resulting in slab crack problems, the thermo-mechanical coupled solidification process in the slab chamferedmold of molten steelhas been mathematical simulated by using the commercial finite element software ANSYS. The slab shell shrinkage and deformation can't be made up effectively by putting to use traditional single taper mold. The taper in the upper mold is small particularly by adopted $0.9 \%$ $\sim 1.2 \% / \mathrm{m}$, the corner gap grows is difficult to be restrained, and the shell growth in the corners is blocked.According to the calculation results of the model, chamfered-mold narrow taper is gradual, roughly simplified into two sections: the first section is the distance $0.35 \mathrm{~m}$ from near the meniscus, the larger taper has been adopted and average taper is $2.16 \%$; The second section is distance $0.35 \mathrm{~m}$ from the meniscus to the mold exit, the smaller taper has been adopted and average taper is $1.31 \%$.
\end{abstract}

\section{1 introduction}

Chamfer parts gaps have been always appeared, which leads to the occurrence of cracks and other defects in the application process of a factory's slab continuous casting chamfered-mold. It is no longer application for narrow face copper plate in accordance with the conventional rectangular mold taper installation. chamfered-mold should be design to adapt its thermal shrinkage in process of internal molten steel solidification in order to reduce the gap and improve the cooling conditions (especially the chamfered position) and increase of the shell thickness, improve the drawing speed and the surface quality, at the same time, the shell surface temperature returning phenomenon will be eliminated or reduced [1], and cracks and deformation of slab has been prevented [2]. The molten steel solidification shrinkage in the mold can't be tracked and measured by experiment instrument in the actual production. Domestic and foreign scholars have done a lot of research work such as Thomas, Park and Junze Jin, Engang Wang, Kaike Cai [3-8] and others have carried out in-depth study of molten steel solidification and shrinkage in mold, and have made a series of achievements.

The ANSYS finite element software has been used to study thermodynamic coupling numerical simulation on heat transfer and solidification and shrinkage deformation of slab in continuous casting chamfered-mold. The effect of mold powder and air gap on the heat transferhas been considered. Temperature field and deformation of slab in the mold have been analyzed in the condition of narrow face copper plate in a chamfered, and a theoretical basis for the optimization of chamfer-mold narrow side taper has been provided by this analysis.

\section{The establishment of thermo- mechanical coupling model}

Fig.1 is a 1/4 slab mold thermo-mechanical coupled finite element model, and 2D slice method of moving coordinate system has been used, which ignoring the heat transfer in the direction of casting. The symmetry of the structure and boundary conditions has been considered, the model is simplified to mold $1 / 4$ cross section.Height of the mold is $900 \mathrm{~mm}$ and the distance from meniscus to mold upper is $70 \mathrm{~mm}$, the size of slab cross section is $250 \mathrm{~mm} * 2000 \mathrm{~mm}$, copperplate thickness is $45 \mathrm{~mm}$, the drawing speed is $0.95 \mathrm{~m} / \mathrm{min}$.

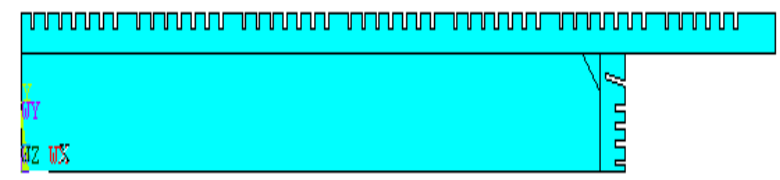

Fig.1 1/4 slab mold thermo-mechanical model 


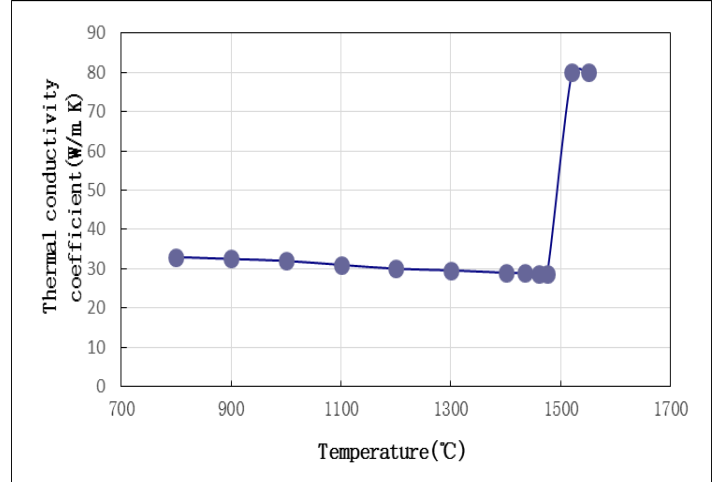

a)

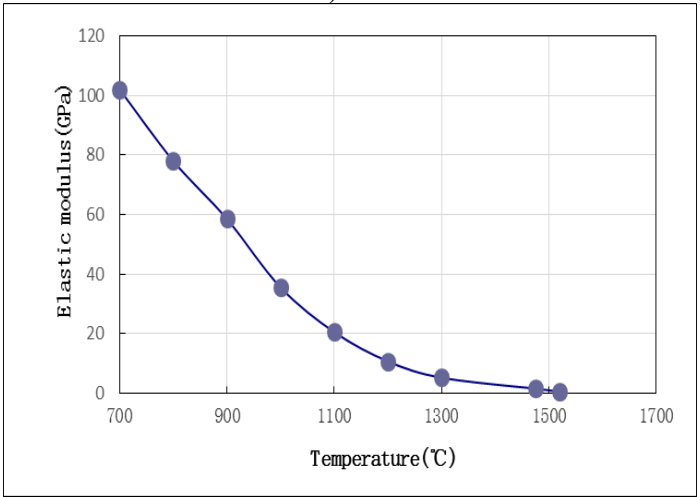

c)

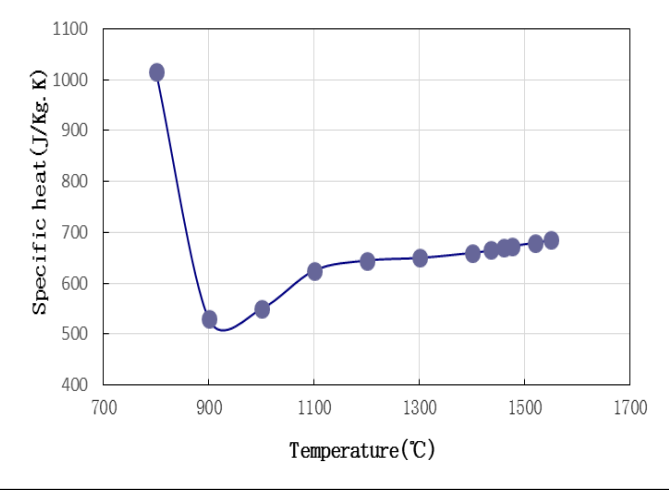

b)

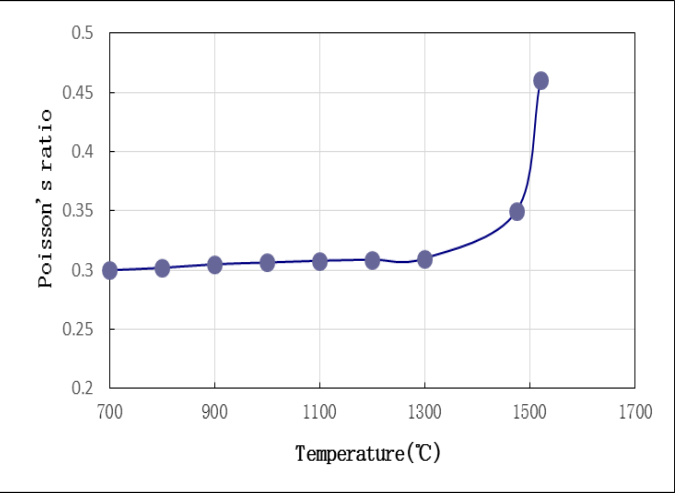

d)

Fig.2 Material parameters of steelunder different temperatures a)Thermal conductivity coefficient; b)Specific heat;c)The elastic modulus; d)The Poisson's ratio

The material physicalparameters such as Thermal conductivity coefficient, Specific heat, elastic modulus and Poisson's ratio of steel is shown in Fig.2. The material physicalparameters of the mold copper plate as shown in Table 1.

Table 1 physical parameters of mold copper plate

Physical parametersThermal conductivitySpecific heatDensity Modulus of elasticity Poisson's ratio

$\left(\mathrm{W} / \mathrm{m} .{ }^{\circ} \mathrm{C}\right) \quad\left(\mathrm{J} / \mathrm{Kg} .{ }^{\circ} \mathrm{C}\right)\left(\mathrm{Kg} / \mathrm{m}^{3}\right)(\mathrm{GPa})$

Value38070089401100.36

\section{Results and discussion}

\subsection{The calculation results of models and analysis}

Fig. 3 ad Fig.4 is slab temperature field nephogram and isograms respectively in the outlet of chamfered-mold;Fig.
5 is temperature changes with the slab casting direction in the typical position of mold; Fig.6 istemperature distribution of slab cross-section outer surface at the outlet of the mold. The joint range of numbers in Fig. 6 is that: along outer surface of the slab,wide face node within the distance $200 \mathrm{~mm}$ from narrow edge, the corner nodes, and each node in the 1/2 narrow face. In Fig.6, left is node of wide face, middle is corner nodes and right is node of narrow face. 


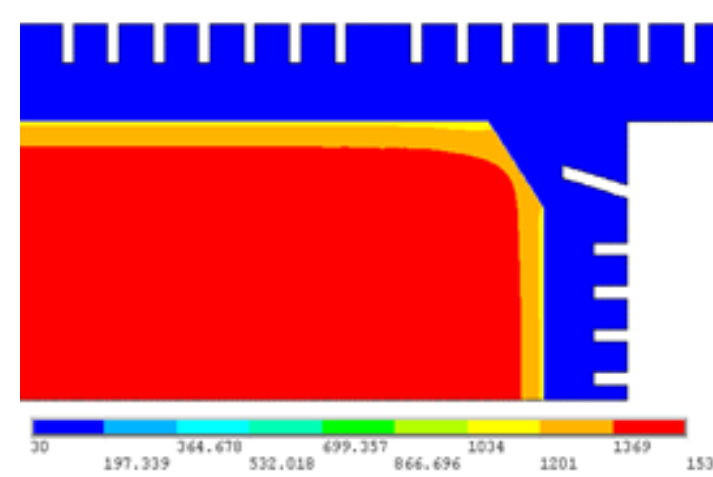

Fig. 3 Slab temperature field

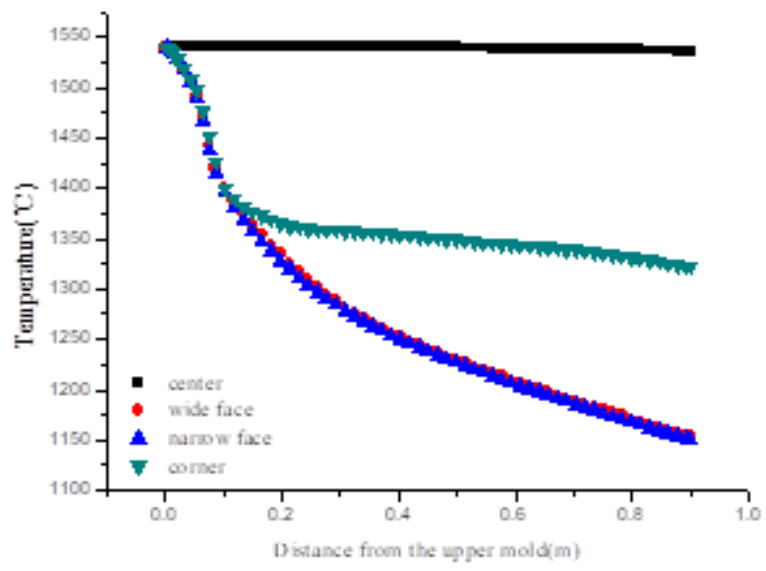

Fig. $5 \mathrm{Slab}$ temperature variation in the casting direction

As you can see from Fig.5, the slab surface temperature decreased. However, there has very big difference in temperature decline rate between the surface and chamfer parts of slab, which makes the mold exit of slab surface temperature significantly lower than that of the surface temperature of chamfer. The temperature of slab wide face and narrow face continued to decline, because the area of slab and mold copper contact closely, the cooling effect is good. For chamfer part of slab, surface temperature decreased rapidly only in the meniscus region and the temperature decline has obviously slowed down in other regions, this is because the corner gap formation, resulting in cooling effect reduced.

Fig. 5 and Fig. 6 shows that: in casting begins, the surface temperature of mold corner regions decreased

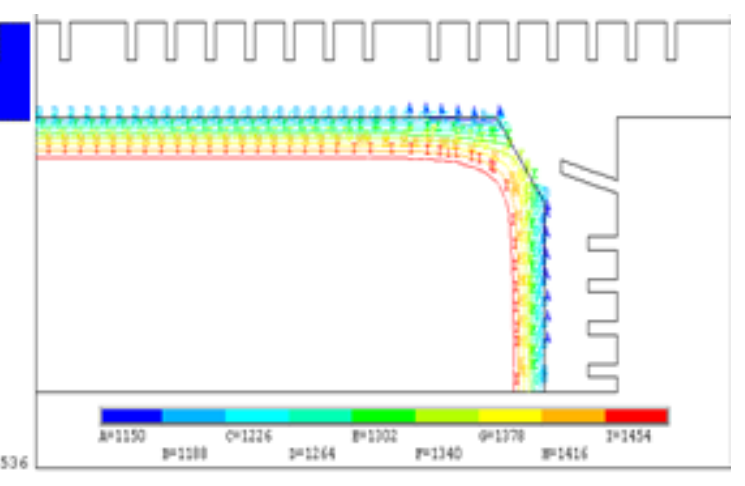

Fig.4 Slab temperature field isograms in

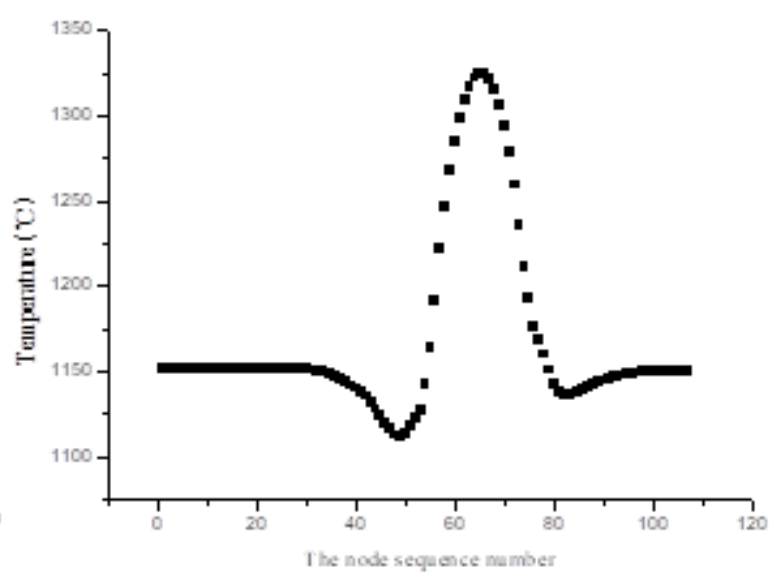

Fig.60uter surface temperature distribution of the slab cross-section

rapidly,due to the effect of two-dimensional heat transfer, the temperature is low, air gap is also the first began to form in the region.The air gap area is increasing with the withdrawal of casting, leading to the high temperature of chamfer parts. The highest temperature of chamfer part is $1324^{\circ} \mathrm{C}, 174^{\circ} \mathrm{Chigher}$ than surface temperature of slab(surface temperature is $1150^{\circ} \mathrm{C}$ )

Fig. 7 is shrinkage of each typical position along the casting direction in the chamfer-mold; Fig. 8 is shrinkage distribution of cross-section of the outer surface of the slab at the mold exit. The node number range of Fig. 8 is: along the outer surface of slab, each node of chamfered corner and $1 / 2$ narrow face. The left side of the Fig.8is the chamfered corner nodes, the right side is the narrow face nodes. 


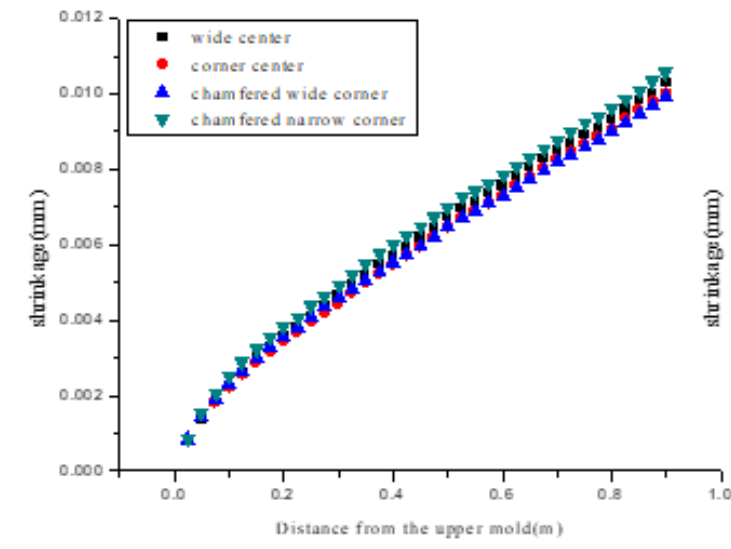

Fig.7 The slab shrinkage of typical position along the casting direction

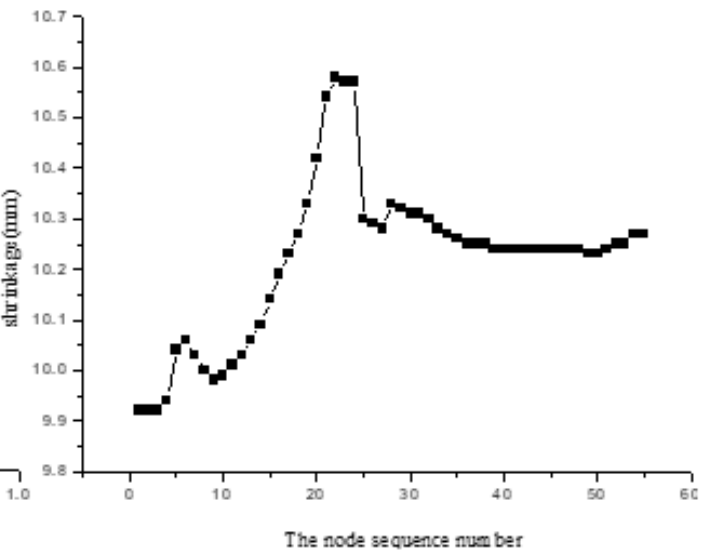

Fig.8 The slab Shrinkage of the outer surface on cross-section
It can be seen from Fig.7, the interface of air gap width of slab and the mold walls is not a linear increase with the slab moving down in the mold, gap increases faster in the upper mold and increasing speed is slow at lower. Therefore, using the traditional single taper mold cannot effectively make up the shell shrinkage deformation, especially in the upper mold region, generally adopts a taper $0.9 \% \sim 1.2 \% / \mathrm{m}$ is small, difficult to restrain the growth of corner gas gap, so that the corner of slab shell growth is blocked. Faraway corner zone is thin and as the crack sensitive area the existence of stress concentration.

Fig. 8 shows, in the mold exit, maximum shrinkage of slab cross section in an outer surface is in the junction of chamfer and the narrow face, the maximum contraction amount is $10.6 \mathrm{~mm}$, while the shrinkage amount of narrow face center is $10.3 \mathrm{~mm}$. So the mold tape design according to the maximal surface shrinkage of slab narrow face is unreasonable.

\subsection{The mold taper optimization}

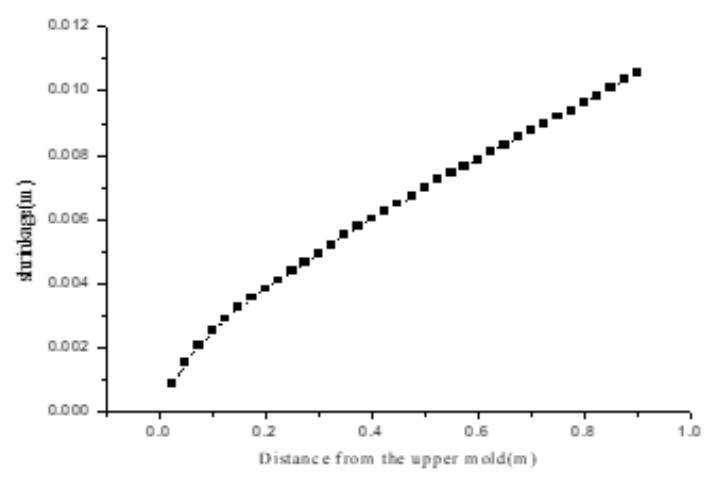

Fig.9 Shrinkage of slab chamfer narrow corner along the casting direction

The chamfered-mold taper should be set according to chamfer narrow face corner point because chamfer corner point in narrow faceshrinkage maximum according to the results of finite element calculation. Chamfered-mold narrow face taper is a gradual taper (see Fig. 10) according to the definition formula of taper (see formula 9) and finite element calculation results (see Fig. 9). This continuous
The shape of mold inner are processed into the upper big and the under small in the manufacture, which has a certain taper in order to reduce the hinder role of air gap on the heat dissipation capability in mold.There is strict requirements in the mold taper selection, which not enough to make up for the air gap between slab and the mold wall when the tape is too small and not conducive to the slab cooling, which will increase the withdrawal resistance, defects such as transverse crack can be appeared and withdrawal unprosperous when seriously.

How to restrain the air gap growth and how to reduce the friction force must be considered at the same time in the optimization of the mold taper design. This is a pair of contradictory factors because the former requires the larger taper and the latter requires smaller taper. Therefore these two factorsneed to be considered in the design of the mold taper, to suppress the air gap growth under the condition of withdrawal resistance is as small as possible.

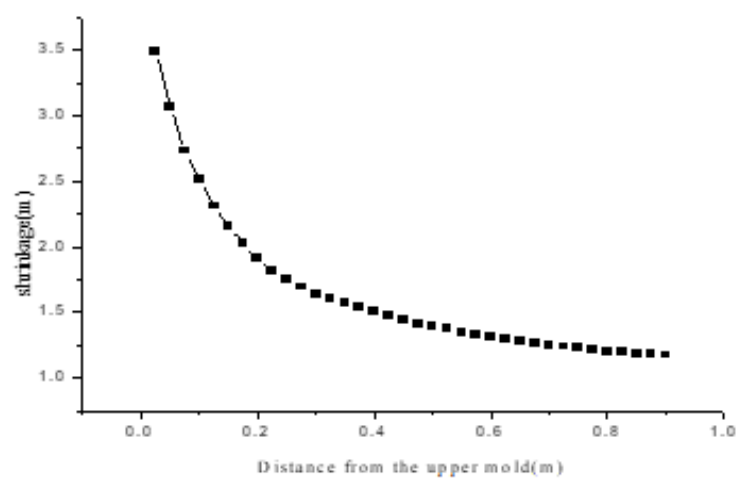

Fig.10 Chamfer-mold taper along the casting direction

gradient taper can be generally simplified into two sections: the first section is $0.35 \mathrm{~m}$ distance from the mold upper opening to near the meniscus, large taper should be used in this section and average is $2.16 \%$; from $0.35 \mathrm{~m}$ distance of the mold upper opening to the mold exit, smaller taper should be used and average is $1.31 \%$. The mold exit taper is $1.17 \%$. 


\section{Conclusion}

Chamfered- mold narrow face taper is a gradual taper can be got because the air gap in upper moldincreases faster andincreases slower at lower.This continuous gradient taper can be generally simplified into two sections: the first section is $0.35 \mathrm{~m}$ distance from the mold upper opening to near the meniscus, large taper should be used in this section and average is $2.16 \%$; from $0.35 \mathrm{~m}$ distance of the mold upper opening to the mold exit, smaller taper should be used and average is $1.31 \%$. The mold exit taper is $1.17 \%$.

\section{Reference}

1. Kaike Cai, Pouring and solidification [M]. Beijing: Metallurgical Industry Press, 1987.

2. Yuanfeng Cao, Yongxin Zhang, Baosheng $\mathrm{Xu}$, etc. Study on the small billet continuous caster mold[J]. Steel making, 1997,13(2):48-52.

3. BRIAN G T, LI G, MOITRA A, et all. Analysis on thermal and mechanical behavior of copper molds during continuous casting of steel slabs. $80^{\text {th }}$ Steelmaking Conference[C].Chicago, USA, April, $13^{\text {th }}-16^{\text {th }}, 1997$.
4. PARK J K, SAMARASEKERA I V, BRIAN G T. Analysison thermal and mechanical behavior of copper mould during thin slab casting. $83^{\text {th }}$ Steelmaking Conference [C]. Pittsburgh, USA, March. 26 $6^{\text {th }}-29^{\text {th }}, 2000$.

5. Junze Jin, Xianshu Zheng, Keren Guo, etc. Numerical simulation of solidification process on continuous casting billet [J]. Iron and Steel,1985,20(5):19-27.

6. Li Kang, Engang Wang, Jicheng He. The numerical simulation of temperature field and the thermal deformation on continuous casting mold [J]. Journal of materials and metallurgy,2006,5(3):190-194.

7. Li Kang, Yang Wang, Engang Wang, etc. The numerical simulation of thermal and stress state of continuous casting billet in mold [J]. Metallurgy in china,2007,1(5):30-34.

8. Kaike Cai, Continuous casting [M]. Beijing: Science Press, 1990.

9. Song Lei, Shan Zeng, Zhiwei Han, etc. Solidification and shrinkage behavior of especially thick slab in different chamfered-mold $[\mathrm{J}]$. Continuous casting, 2013, (2):5-11.

10. Han H H, Lee J E, Yeo T J, et al. A Finite Element Model for 2-Dimensional Slice of Cast Strand[J]. ISIJ International, 1999, 39(5):445. 